\title{
Magicoterapia: O uso de Mágicas Contextualizadas como Instrumento para auxiliar na Ludoterapia
}

\author{
José Demontier Guedes ${ }^{1}$; Francisco Robson de Brito Gonçalves ${ }^{2}$
}

\begin{abstract}
Resumo: Este Artigo apresenta concepções sobre o uso de mágicas na terapia infantil e os efeitos no processo psicoterapêutico. O trabalho tem como objetivo geral inserir a mágica como instrumento para facilitar a comunicação entre terapeuta e paciente. Quanto aos objetivos específicos, busca-se analisar a percepção das crianças diante da técnica utilizada, despertando o interesse pelo tema através da contextualização com apresentação de truques e estimular o relato sobre a queixa através da observação e da escuta. O método utilizado para o desenvolvimento da pesquisa ocorreu pela análise de experiências do uso de mágicas aplicadas na Educação Infantil da Rede Pública de Ensino Municipal e, também em sessões de psicoterapia. Os relatos apresentados fazem parte da experiência dos próprios autores e refletem a realidade da necessidade de inovar para adquirir melhores resultados, visto que a arte da mágica como instrumento, possui características peculiares capaz de desenvolver na criança habilidades cognitivas para o seu desempenho e relação com o outro, atuando na fixação de ideias implícitas mediante a contextualização com o assunto de interesse em investigação. A mágica é uma excelente estratégia e um instrumento de apoio, capaz de falar a linguagem para qualquer público quando bem aplicada. Em razão disto, tem-se como finalidade apresentar essa técnica inovadora para ser aplicada na terapia infantil.
\end{abstract}

Palavras-chave: Psicologia. Terapia infantil. Mágica.

\section{Magic Therapy: The Magic of use contextualized a tool to assist in Ludotherapy}

This article presents views on the use of magic in child therapy and the effects in the psychotherapeutic process. The work has as main objective to enter the magic as a tool to facilitate communication between therapist and patient. As for specific objectives, we seek to analyze the perception of children on the technique used, arousing interest in the subject through the context with the presentation of tricks and stimulating account of the complaint by observing and listening. The method used to develop the research was the analysis of the use of magical experiences applied in kindergarten Public Network Municipal Education and also in psychotherapy sessions. The reports presented are part of the experience of the authors and reflect the reality of the need to innovate to get better results, as the magic of art as an instrument, has peculiar characteristics able to develop in children cognitive skills for their performance and relationship with the another, working on fixing ideas implied by context with the subject of interest in research. Magic is an excellent strategy and tool support, able to speak the language to any public when properly applied. Because of this, we have intended to present this innovative technique to be applied in child therapy.

Keywords: Psychology. Child therapy. Magic.

\footnotetext{
${ }^{1}$ Mestre em Ciências da Educação. Psicólogo. Pedagogo. Especialista em Português e arte/educação. Habilitação para o ensino das línguas Portuguesa e Inglesa. Mentor/Educador Social na prevenção ao uso de drogas e violência em escolas públicas e privadas na Região do Cariri Cearense através do Programa Educacional de Resistência às Drogas e à Violência - PROERD. Responsável pelo setor de Orientação Educacional e Psicossocial do Colégio da Polícia Militar do Ceará com sede em Juazeiro do Norte/CE.

Autor correspondente: e-mail: proerddemontierguedes@gmail.com;

${ }^{2}$ Mestre em Ciências da Educação pelo Instituto Superior de Educação Professora Lúcia Dantas - ISEL (2015) Brasília/DF, Especialista em Matemática e Física pela Faculdade de Juazeiro do Norte - FJN (2013) e Graduação em Tecnologia em Eletromecânica pelo Instituto Centro de Ensino Tecnológico CENTEC (2007).
} 
Id on Line Revista Multidisciplinar e de Psicoloqia

Id on Line Multidisciplinary Journal and Psycology

\section{Introdução}

O discurso sobre o processo terapêutico tem estimulado o debate entre os profissionais de psicologia, especialmente no atendimento clínico, palco de uma diversidade de indivíduos, os quais procuram respostas para seus conflitos, sejam eles internos ou externos, e, diante disso, passam a receber atenção mediante o processo de escuta objetivando a valorização da vida.

Nesse contexto, desenvolver a autonomia dos sujeitos a fim de levar a reflexão mediante determinados comportamentos e demandas trazidas por eles, passa a ser o foco principal da psicoterapia para estabelecer uma relação confiável, facilitar o vínculo e favorecer o processo de terapêutico.

A interação entre paciente e terapeuta é citada por Souza (2012) como um momento confortável e sem constrangimentos, possibilitando uma relação de confiança. De acordo com o autor, este é um processo de acolhimento e reflexão, influenciando diretamente no sucesso do tratamento, que dependerá do manejo do terapeuta, para criar uma aliança e o fortalecimento do individuo mediante a colaboração de ambos com utilização de técnicas psicológicas adequadas em cada caso.

O presente artigo pretende ressaltar reflexões para atuação do psicólogo na terapia infantil, enfatizando a necessidade de trabalhar com novas técnicas, pois se sabe que, em alguns casos, há certa dificuldade em extrair das crianças suas reais queixas, as quais são informadas pelos pais ou responsáveis.

Nesse sentido, buscou-se também, divulgar a magicoterapia como instrumento de análise no atendimento infantil para possibilitar a possível ampliação deste e alcançar uma maior interação nas sessões, além de propor aos profissionais da área da psicologia, outros meios de comunicar-se com as crianças.

A pesquisa visa ainda contribuir na elaboração de estratégias que possam fortalecer a tomada de decisão e a escolha de comportamentos positivos, levando os indivíduos a pensar sobre a situação, analisar as escolhas, decidir de forma confiante e avaliar sua postura diante de situações que exijam maior reflexão sobre determinadas questões. Nessa linha de pensamento a magicoterapia pode ajudar na identificação das queixas e facilitar a observação de comportamentos e patologias que possam comprometer a saúde física e mental dos pacientes, buscando reduzir a vulnerabilidade e fortalecer a autonomia dos sujeitos.

Assim, percebe-se que as inovações no processo de terapia infantil é algo essencial e que deve ter início na clínica, para que possa fortalecer vínculos afetivos, minimizar os prejuízos quanto ao rendimento nos atendimentos e proporcionar aos pacientes oportunidades para exercer sua autonomia e melhorar a qualidade de vida. 
Partindo desse pressuposto, objetiva-se inserir a mágica como instrumento para facilitar a comunicação entre terapeuta e paciente, partindo da análise da percepção das crianças diante da técnica utilizada, visando despertar o interesse pelo tema através da contextualização com apresentação de truques para estimular o relato sobre a queixa.

Durante a pesquisa inúmeras atividades com utilização de mágicas foram realizadas, tanto no atendimento clínico, como também em sala de aula, através de instruções educacionais com crianças na faixa etária de 09 a 12 anos.

Por esse instrumento lúdico, veicula-se a possibilidade de uma abordagem diretiva e eficiente, podendo despertar nos terapeutas a consciência de inovações, a fim de promover a criatividade para que a criança sinta-se segura diante da complexidade de informações e, com isso, expressar-se de forma espontânea as queixas a serem investigadas.

No decorrer dessa pesquisa, observou-se que os recursos levados ao encontro das crianças as tornam mais atentas e aptas a distinguir e compreender melhor os questionamentos propostos na terapia. Nessa perspectiva, a análise feita por Karling (1991) ainda sobre esse tema, é que há o favorecimento da estruturação da aprendizagem cognitiva, compreensão e, principalmente a comunicação possibilitando um vínculo afetivo.

\section{Uma Abordagem Lúdica na Terapia}

Winnicott (1995) considera o lúdico prazeroso. Luckesi (1999) ver as atividades lúdicas como uma satisfação pela entrega da atenção ao prazer, afirmando ainda que há uma inter-relação entre o inconsciente e o mundo externo na construção da identidade pessoal e coletiva. Para o autor, é uma forma de garantir a liberdade da criatividade humana.

Observa-se que ambos os autores percebem a capacidade do indivíduo absorver o conhecimento de forma intensa, em todos os sentidos, através de um clima agradável e entusiástico. São esses aspectos que favorecem um forte teor emocional de envolvimento capaz de gerar um estado vibrante de euforia.

Nesse contexto, observa-se que as atividades lúdicas possibilitam de forma pragmática o desenvolvimento pessoal, social e cultural, além da incorporação de valores e assimilação de novos conhecimentos. Assim, o terapeuta auxilia a criança a manter-se equilibrada entre o real e o imaginário por ela vivenciada de forma prazerosa.

Para Luria (1992) as funções mentais superiores surgem da interação entre os fatores biológicos com os fatores culturais, que ocorrem nesse processo evolutivo de cada ser humano. 
Id on Line Revista Multidisciplinar e de Psicoloqia

Id on Line Multidisciplinary Journal and Psycology

Quanto à evolução para o desenvolvimento humano, a Psicologia do Desenvolvimento aborda o tema através de diferentes autores:

- Segundo a teoria defendida pelos Ambientalistas, destacando Skinner e Watson (behavioristas), as crianças nascem como tabulas rasa, assim como uma folha de papel em branco, que em meio ao ambiente inserida vão aprendendo por processos de reforço ou imitação.

- Ao contrário dos Ambientalistas, os teóricos Inatistas, assim como Chomsky, tem a concepção que as crianças já nascem com a capacidade de desenvolvimento em virtude de terem tudo na sua estrutura biológica, pois segundo essa teoria, nada é aprendido no ambiente, e sim apenas acelerado por este.

- Já os Construcionistas, como o emblemático Piaget, têm como princípio de que o desenvolvimento de um indivíduo se dá pela interação entre o desenvolvimento biológico e as aquisições da criança com o meio. Sobre a ótica Sociointeracionista, cujo precursor é Vygotsky, parte da ideia de que o desenvolvimento humano consiste nas trocas sociais entre parceiros, através da mediação e interação entre ambos.

- Para os teóricos Evolucionistas, motivados pela teoria de Fodor, afirmam que o desenvolvimento humano é o produto de uma interação de processos genéticos e ecológicos, os quais envolvem experiências individuais de cada indivíduo, conforme as características humanas e suas variações antes mesmo do nascimento.

- Para a perspectiva Psicanalítica, figurado por Freud, Klein, Winnicott e Erikson, busca compreender o desenvolvimento humano através do consciente e inconsciente da criança, priorizando seus conflitos internos na infância até o término do ciclo vital.

Assim, acredita-se que para entender a evolução e a complexidade do desenvolvimento humano, é preciso ter uma postura sistêmica capaz de integrar os múltiplos subsistemas do individuo.

\section{A Mágica como base de um Estudo Científico}

Atualmente, a mágica é vista como um entretenimento. No Brasil, a profissão de Mágico, está implicitamente na Lei Nacional $n^{\circ} 6.533$, de 24 de maio de 1978, regulamentada pelo Decreto $n^{\circ}$ 82.385, de 05 de outubro de 1978. Apesar da data de regulamentação, ao contrário do que muitos pensam, o dia do Mágico é comemorado no dia 31 de janeiro, que segundo a história, faz jus a data de falecimento de são João Bosco, que se beneficiava dessa arte, por trabalhar como mágico, acrobata e malabarista, sendo homenageado e considerado como sendo o padroeiro dos mágicos. 
Id on Line Revista Multidisciplinar e de Psicoloqia

Id on Line Multidisciplinary Journal and Psycology

Um pressuposto importante para uma boa apresentação da mágica se trata da conciliação dos mecanismos técnicos com a capacidade intrapessoal peculiar a cada pessoa, para que este possa ser desenvolvido e o espectador se identifique com o que o mágico está fazendo. "É como se fosse uma metáfora, uma imagem de algo em sua realidade" (ÁVILA, 2012, p. 20).

Quanto aos locais de uso desta técnica, atualmente, com os aspectos inovadores advindo com os avanços tecnológicos, as mágicas acompanharam vertiginosamente essas mudanças em relação às apresentações. Ao contrário do que muitos pensam, nem sempre as apresentações ocorrem em lugares especiais cheios de efeitos em um cenário arrojado. Com isso, o espaço de apresentação saiu dos palcos e ganhou as ruas e assim, qualquer lugar passou a ser adequado para uma apresentação que busca aparentemente fazer coisas impossíveis acontecerem.

Por conta disso, o uso da mágica contextualizada na terapia se realiza como um ambiente inovador capaz de despertar surpresas e expectativas diante do inesperado, possibilitando então, a interação mediante atenção do paciente pelo truque.

Uma reportagem na revista Scientific American Brasil traz um debate importante quanto ao uso desta técnica, relacionada à questão do uso da mágica e dos truques iludirem o cérebro.

Gravenor (2014) revela o interesse de neurocientistas por esta técnica. Ele relata que os neurocientistas estão se familiarizando com os métodos da mágica ao submeter à própria mágica ao estudo científico, demonstrando, em alguns casos, pela primeira vez, como alguns de seus métodos atuam no cérebro.

Estudos feitos até agora sobre a mágica confirmam o que se conhece sobre a cognição e a atenção a partir de trabalhos anteriores na psicologia experimental (GRAVENOR, 2014).

Em pesquisa, o autor ainda acrescenta que os métodos da mágica também podem ser colocados em prática para "induzir" pacientes a se concentrarem nas partes mais importantes de sua terapia, evitando distrações que provocam confusão e desorientação. $\mathrm{O}$ autor ainda acrescenta que a mágica é caracterizada como base de estudos neurológicos para melhor entender o cérebro e as bases neurais das funções cognitivas. Nessa perspectiva, conclui-se que as informações implícitas também são importantes tanto para a percepção de um truque quanto para sua reconstrução.

\section{O uso de Mágicas como Arte na Ludoterapia}

Axline (1984) diz que a ludoterapia é baseada na autoexpressão da criança. Pois dá a oportunidade da mesma se libertar de seus sentimentos e problemas através do brinquedo, sendo este o modo de falar das crianças, que naturalmente vai expressando seus anseios e dificuldades. Segundo a 
autora, a ludoterapia pode ser direta, quando o terapeuta assume a responsabilidade de orientação e interpretação, e não direta, quando a responsabilidade e a direção ficam para as crianças.

Libertando-se desses sentimentos através do brinquedo, ela se conscientiza deles, esclarece-os, enfrenta-os, aprende a controlá-los ou os esquece. Quando ela atinge certa estabilidade emocional, percebe sua capacidade para se realizar como individuo e pensar por si mesma, tomar suas próprias decisões, tornar-se psicologicamente mais madura e, assim, tornar-se pessoa (AXLINE, 1984, p. 28).

A autora, em relação à sala de ludoterapia conclui:

A sala de ludoterapia é um lugar de crescimento. A criança é a pessoa mais importante, onde ela está no comando da situação e de si mesma. Onde ninguém lhe diz o que fazer ou nem critica o que faz, ninguém a importuna, faz sugestões, estimula-a ou intromete-se em seu mundo particular, subitamente ela sente que pode abrir suas asas, pode olhar diretamente para dentro de si mesma, pois é aceita completamente. É uma experiência única para a criança descobrir de repente que as sugestões, ordens, recriminações, restrições, críticas, desaprovações, ajudas e instruções dos adultos desapareceram. Tudo isso é substituído pela aceitação completa e pela situação permissiva que lhe possibilita ser ela mesma (AXLINE, 1984, p. 28-29).

Nesse processo, o terapeuta deve ser um bom observador. Na ludoterapia, a criança é aceita como ela é, e não como as pessoas querem que ela seja.

Nessa linha de estudo, os brinquedos aparecem como peça fundamental para o processo psicoterápico, pois estes, conforme a autora são o meio natural de autoexpressão da criança.

De acordo com os autores citados nessa pesquisa, o terapeuta deve interagir com a criança para obter maior rendimento do processo psicoterápico. Esse tipo de relacionamento é feito entre o terapeuta e a criança, permitindo que ela revele seu verdadeiro eu, conseguindo sua aceitação e sua autoconfiança.

Winnicott (1995) relata que é no brincar que a criança e o adulto fluem sua liberdade de criação. Acrescenta que a psicoterapia é efetuada na superposição de duas áreas lúdicas, paciente e terapeuta. Diante disso, destaca-se o brincar porque é desse modo que a criança manifesta sua criatividade.

A partir dos comentários dos autores, houve a possibilidade de introduzir na ludoterapia uma nova técnica, o uso de mágicas como ferramenta norteadora no processo ludoterápico. Essa ferramenta proporciona o entretenimento entre terapeuta e paciente. Desse modo, a mágica é considerada uma arte lúdica e interativa entre o facilitador e o público.

Segundo Valladares (2008) a arte é inerente ao ser humano e, é um meio de expressão, comunicação e de linguagem.

Percebe-se então que a mágica, contextualizada a realidade da criança, gera expectativa e desperta na mesma o interesse pelo tema e a leva ao mundo da imaginação. 
Id on Line Revista Multidisciplinar e de Psicoloqia

Id on Line Multidisciplinary Journal and Psycology

Assim, na contextualização da mágica com a ludoterapia, atuando de forma direta com o objetivo de envolver o público alvo no processo de interação com o terapeuta, busca-se a reconstrução da história e o relato espontâneo sobre a queixa apresentada.

\section{Relato de Experiência}

Como Educadores Sociais do PROERD - Programa Educacional de Resistência às Drogas e à Violência, os autores deste artigo vem atuando na prevenção ao uso de drogas em escolas públicas e privadas no Estado do Ceará, objetivando manter crianças e adolescentes longe das drogas para garantir uma melhor qualidade de vida.

Para tanto, utiliza-se uma metodologia dinâmica, através de estudo de caso, jogos pedagógicos sobre drogas, e nos últimos anos a inclusão do uso de mágicas contextualizadas para melhorar a atenção dos jovens perante as explicações do conteúdo e facilitar o processo de ensino-aprendizagem.

Nessa perspectiva, os resultados foram satisfatórios, nos quais, percebeu-se maior engajamento dos alunos nas atividades e um número considerável de participações nos debates, pois ao contextualizar o tema das aulas com as mágicas, os estudantes ficavam mais alerta, mesmo que motivados a descobrir o segredo dos truques utilizados, porém ouviam claramente as explicações e, que muitas vezes atuavam como atores principais, ou seja, com posturas transformadoras, fortalecendo os espaços para o diálogo, gerando a promoção de oportunidades para se expressarem de forma criativa.

Diante do sucesso nas aulas desenvolvidas pelo Programa PROERD, e como estudante do Curso de Psicologia, mediante as sessões de terapia infantil nos estágios, foi utilizada a mágica na tentativa de diversificar o atendimento psicoterápico.

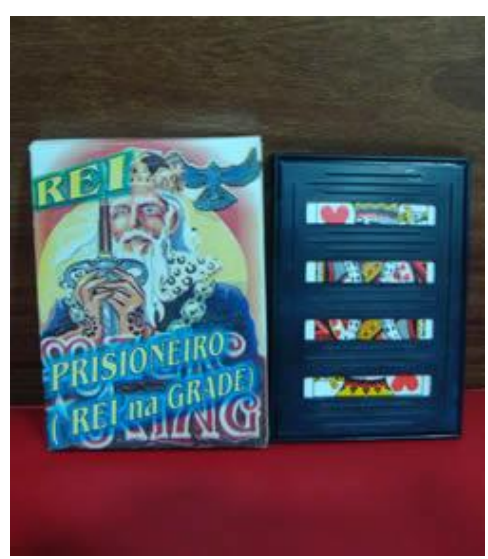

Exemplificando o uso desta técnica, foi utilizada a mágica, "rei na grade", contextualizada com a queixa de uma criança em atendimento. Simulou-se que o rei aparece livre antes de iniciar o truque, no entanto, ao não cumprir com suas obrigações e adotando uma postura contrária ao seu posto de rei, acabara sendo privado de sua autoridade e de coisas que gosta de fazer. 
Desse modo, ao se comparar ao rei, o sujeito passa a perceber que para conquistar algo de seu interesse, deve-se adequar-se a realidade em que está inserida e estabelecer métodos para garantir sua autonomia.

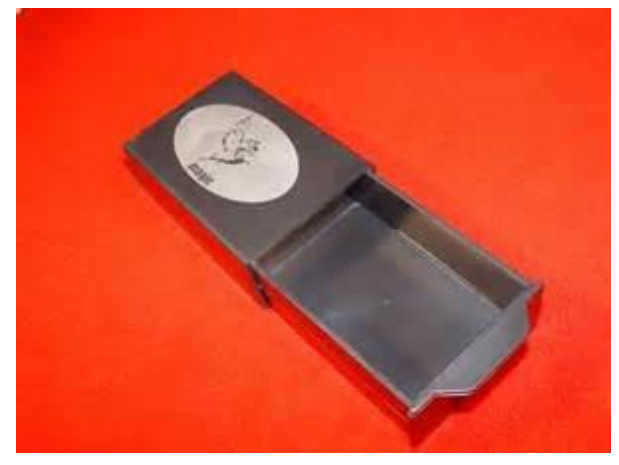

Em outro momento, como nova experiência, a mágica utilizada foi "a caixinha de surpresa", onde esta aparentemente vazia, verificada pela criança, começa a sair vários tipos de lenços coloridos, os quais representam a probabilidade de algo continuar acontecendo, mesmo não sendo percebido.

Desse modo, também contextualizada com a queixa da criança, mostrando para ela a necessidade de refletir sobre sua atual situação, procurando mudar determinados comportamentos, quando for o caso e, realizar o que puder para sentir-se bem, sabendo que a situação pode se agravar, mesmo quando não percebemos algo que comprometa o bem-estar.

Para concluir, buscou-se levar a criança a entender que é importante falar sobre seus problemas e limitações, pois assim, pode-se evitar o agravamento e melhorar a qualidade de vida. Pelas experiências apresentadas, através da utilização de mágicas, observou-se que estas foram significativas para o processo de interação e comunicação entre paciente e terapeuta, visto que além da atenção demonstrada pelas crianças na hora da realização dos truques, houve o interesse pelo tema, opinando sobre o desfecho das histórias e, consequentemente, ficaram mais à vontade para se expressar.

A inclusão desta técnica na terapia trouxe expectativas para as próximas sessões, haja vista que ao chegar perguntavam se haveria mágicas. É importante esclarecer, que, o uso de mágicas não será informado durante a sessão, visto que a mágica deve aparecer como uma ferramenta secundária que veiculará como um fator surpresa para que a criança fique atenta a cada passo da terapia e não figure apenas como ouvinte passivo durante todo o processo. 
Id on Line Revista Multidisciplinar e de Psicoloqia

Id on Line Multidisciplinary Journal and Psycology

\section{Metodologia}

A pesquisa foi desenvolvida qualitativamente por meio de variáveis que não podem ser medidas, apenas observadas, como cita Bauer (2002, p.23) "lida com interpretação das realidades sociais".

O desdobramento deste trabalho ocorreu pela análise de experiências do uso de mágicas aplicadas em público infantil, tanto na educação quanto em sessão de psicoterapia e coletas de dados, mediante entrevistas, ocorrendo também a revisão bibliográfica sobre o tema em discussão.

Com relação à verificação dos resultados obtidos, Minayo (2005) diz que, além das atividades previstas, deve-se investigar a percepção, a qual consiste se os resultados finais esperados foram alcançados. As possíveis mudanças em função da técnica utilizada na terapia deve ter um direcionamento na medida específica para determinado resultado, criando possibilidades de retificar e reorientar as ações.

$\mathrm{O}$ aperfeiçoamento do estudo deu-se em cumprir os elementos habitualmente especificados pelos objetivos requeridos quanto à natureza do tema. Para tanto, vivenciou-se a própria experiência pertinente ao tema proposto, sendo a sala de Ludoterapia o habitat principal para a comprovação dos fatos, ora citados.

Assim, conclui-se que a avaliação deste processo com as técnicas inovadoras, no caso a mágica, não é uma ação isolada, mas a integração entre avaliadores e avaliados, em busca do aperfeiçoamento e do comprometimento numa sessão de psicoterapia. Para tanto Gatti $(2004$, p. 14) acrescenta que a análise dos resultados mediante a informação que não pode ser diretamente visualizada, poderá, se tais dados sofrer algum tipo de transformação que permita uma observação de outro ponto de vista.

\section{Resultados e Discussão}

A pesquisa teve como fonte de investigação a inclusão da mágica na terapia infantil e o quanto esta contribui para facilitar o processo de comunicação entre paciente e terapeuta.

Como resultados mais precisos da utilização desta técnica, será exposto a seguir, uma pesquisa realizada entre os jovens que tiveram instruções educacionais com utilização da mágica e sem a utilização do uso de mágicas.

A pesquisa foi realizada com alunos do Ensino Fundamental II, de $6^{\circ}$ e $8^{\circ}$ ano, que participaram do Programa Educacional de Resistência às Drogas e à Violência (PROERD) quando 
Id on Line Revista Multidisciplinar e de Psicoloqia

Id on Line Multidisciplinary Journal and Psycology

estes, ainda cursavam o $5^{\circ}$ ano, entre os quais tiveram oportunidades similares no que tange aos conteúdos de prevenção explícitos, porém com experiências diferentes quanto ao uso das técnicas aplicadas em sala de aula pelo Policial Francisco Robson de Brito Gonçalves, Instrutor do Proerd no Estado do Ceará, o qual buscou mostrar o quanto a mágica, além de melhorar a comunicação, também facilitar a assimilação do conteúdo.

O gráfico a seguir mostra que, em relação à aprendizagem, o uso de mágicas foi o que mais chamou atenção dos alunos.

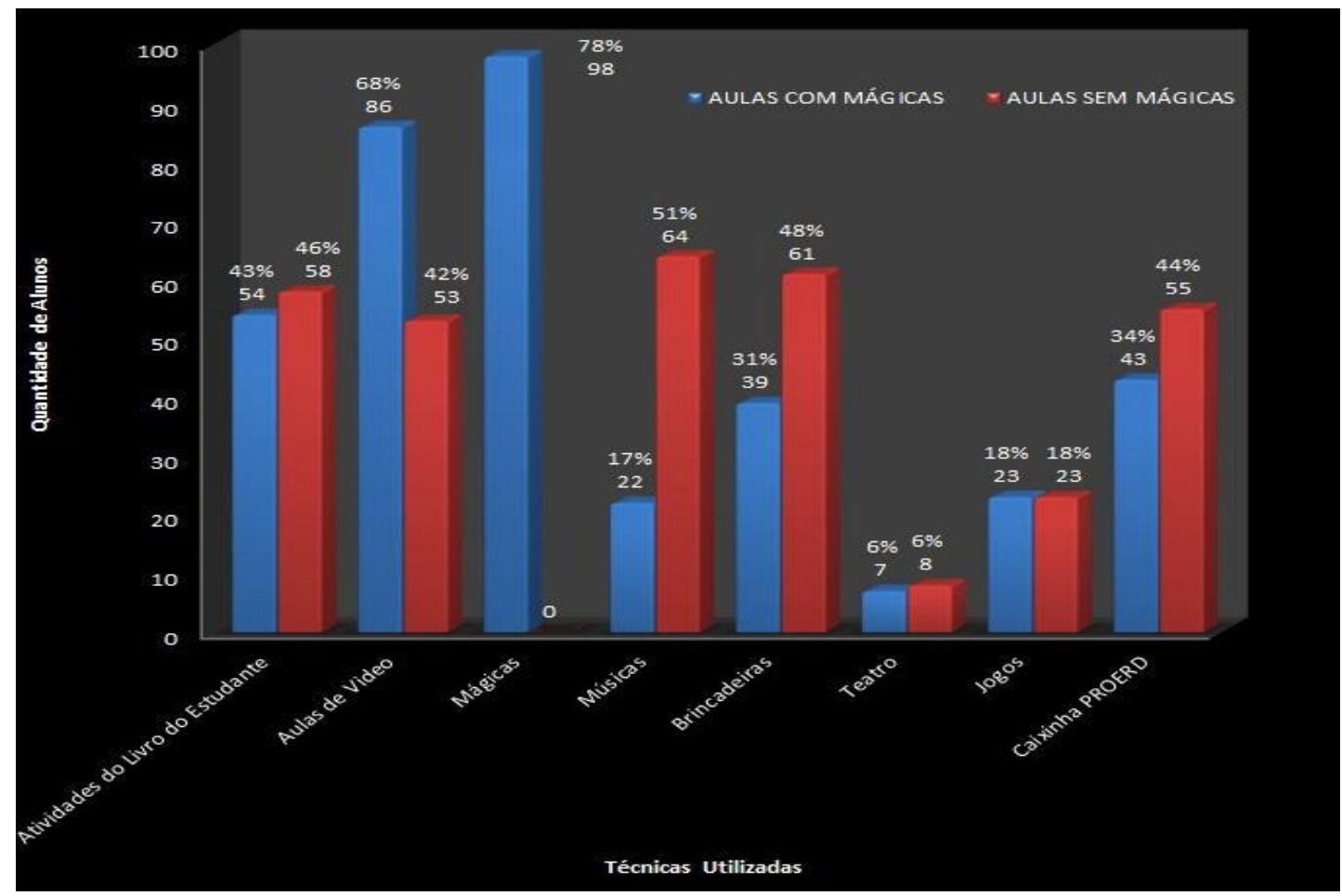

Fonte: dados da pesquisa

Observa-se no gráfico que o uso de técnicas variadas chama atenção dos alunos e desperta o interesse para aprender conteúdos diversos, assim como propõe Karling (1991), diversas técnicas de ensino podem ser utilizadas, para descobrir situações e conseguir motivar seus alunos a estudarem com prazer. Conclui-se, portanto, que um número elevado de 98 alunos se encantou com as mágicas, correspondendo a $78 \%$ dos que tiveram aulas com mágicas.

Ao contrário, o grupo de alunos que não tiveram aulas com mágicas não atingiram o mesmo perfil daqueles que tiveram a mágica como ferramenta de ensino.

Assim, Ávila (2012) afirma: 
Id on Line Revista Multidisciplinar e de Psicoloqia

Id on Line Multidisciplinary Journal and Psycology

É a sensação do encanto, da maravilha, causada particularmente por presenciar um fenômeno completamente distante do mundo real. Abrem-se portas para um mundo completamente diferente, no qual não existem leis nem regras, no qual as pessoas podem acreditar em qualquer coisa, sem medo de ser criticadas. A mágica aproxima a mente de possibilidades infinitas de uma criança... (ÁVILA, 2012, p.16).

O uso da mágica não corresponde apenas ao fato de chamar atenção, mas de abrir a mente para novas ideias e uma forma especial e única de enxergar as coisas. Complementando que o uso de truques de mágica pode promover elevados momentos de ensino, desenvolvimento social e emocional, além de saúde e bem-estar nas crianças em terapia.

Outro dado importante foi que há evidências com relação à pesquisa de que corrobora com o fato da mágica possuir características impressionantes, contribuindo também para uma maior compreensão daquilo que está sendo explanado.

Sobre este fato, o gráfico a seguir diferencia estes jovens quanto ao comportamento durante uma aula com utilização de mágicas.

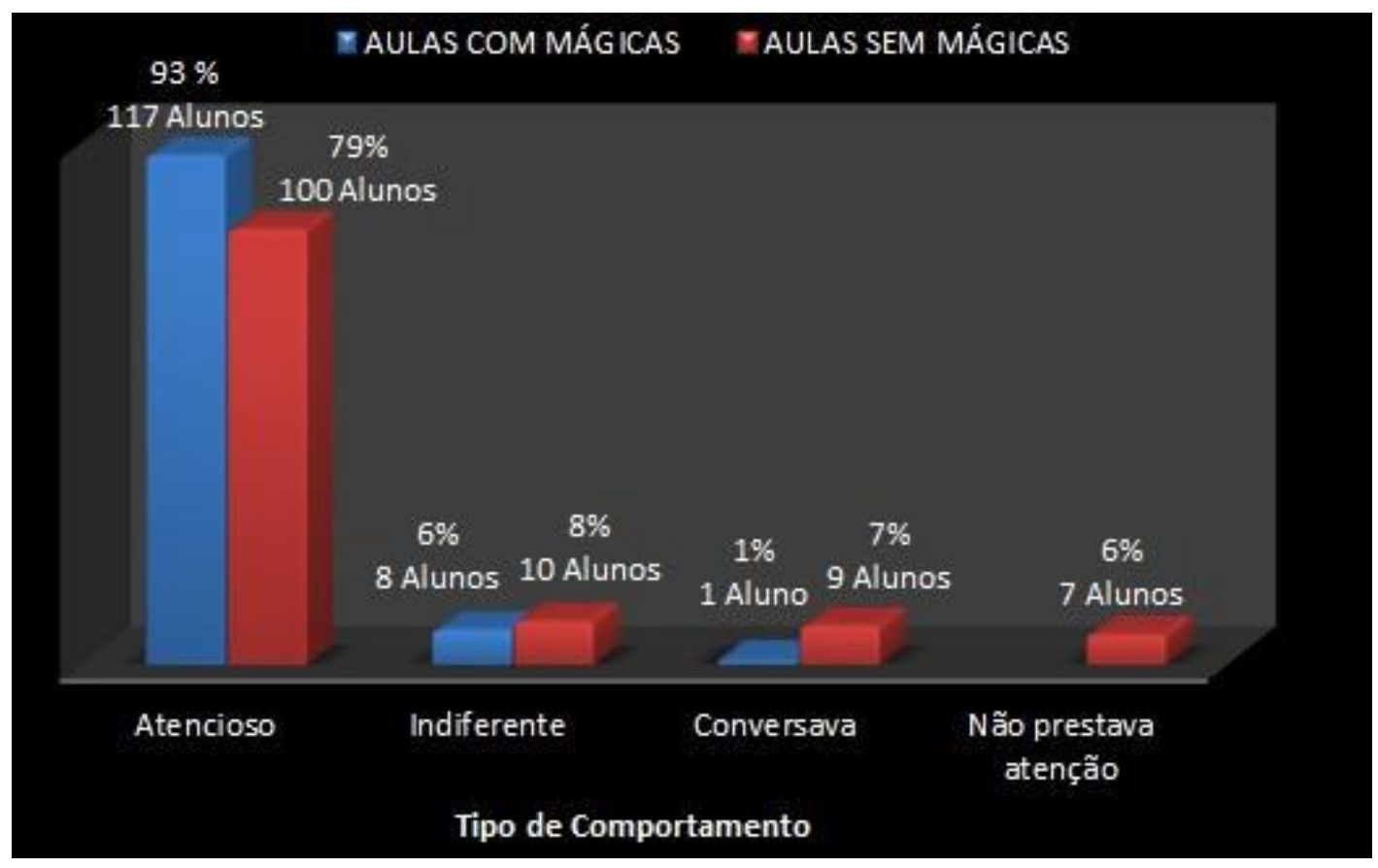

Fonte: dados da pesquisa

Quanto ao gráfico comportamental, entre ambos os casos, a atenção por parte dos alunos que tiveram aulas com mágicas foram maiores que as aulas sem mágicas. O resultado, também, influenciou em outras variáveis, uma vez que nas aulas sem mágicas se comprova um número maior de alunos que se mantiveram dispersos através de conversas, não prestando atenção, bem como o sentimento de indiferença. 
Com relação a este estudo, Vygotsky (2001) postulou a possibilidade de transformar o mundo concreto pelo emprego de ferramentas, estabelecendo condições para mudar suas ações e transformar qualitativamente sua consciência.

Reforça-se então o objetivo desta investigação, que é identificar a percepção das crianças quanto à contextualização do uso de mágicas para facilitar o processo terapêutico. Assim, afirma-se ser a mágica uma ferramenta importante, que contextualiza com o conteúdo abordado, a criança deixa de ser um expectador para se tornar um ator ativo durante todo processo.

\section{Considerações Finais}

No processo de construção desta pesquisa, buscou-se evidenciar a importância da ludoterapia mediante a inclusão de mágicas, para levar a criança a melhorar a comunicação com o terapeuta, levando-a, a refletir sobre sua realidade, trabalhando o seu interior, objetivando reduzir ou remover determinadas queixas.

Neste contexto, o terapeuta atua como facilitador visando estabelecer uma relação de confiança para despertar, naturalmente, na criança em atendimento, a necessidade de comunicar-se com o terapeuta, visando o empoderamento do conhecimento para melhorar a qualidade de vida.

As ações visaram proporcionar a interação de todos os envolvidos no processo psicoterápico. Diante da pesquisa realizada e dos resultados apresentados, conforme está descrito nos gráficos e comentados, destaca-se o desempenho positivo do uso da mágica.

Para tanto, a meta alcançada partiu da necessidade de investigar e comprovar que a mágica pode fazer a diferença na ludoterapia, pois esta passa a ser um atrativo para as crianças, sendo capaz de despertar nelas a necessidade de falar de suas queixas e ajudar o terapeuta a intervir com mais precisão.

Como objeto de estudo, visando conhecer, analisar, avaliar e validar os resultados da pesquisa, o trabalho desenvolvido poderá contribuir para ampliar a discussão sobre o tema entre outros profissionais.

Pelo que foi discutido, a mágica destacou-se como uma estratégia eficaz na educação, podendo esta fazer também a diferença em terapias infantis. Porém, não se pode afirmar algo conclusivo, necessitando de maiores investigações e experiências para comprovação total dos fatos, partindo do entendimento interno do sujeito que a vivencia.

As técnicas de utilização da mágica são planejadas de acordo com a demanda de cada caso e as intervenções com os truques acontecem na medida em que o terapeuta achar necessário utilizar. 
Id on Line Revista Multidisciplinar e de Psicoloqia

Id on Line Multidisciplinary Journal and Psycology

Em síntese, foi colocada em evidência a importância da arte mágica, ao integrar totalmente às atividades lúdicas, dinâmicas e impactantes, levando em consideração sua subjetividade e, principalmente, sua expressividade enquanto técnica facilitadora no processo terapêutico. No entanto, faz-se necessário compreender esta metodologia com certa profundidade teórica para, então, entendermos as possíveis implicações desta expressividade na prática.

Diante das informações e dos dados apresentados, as observações e experiências com esta técnica foram suficientes para diagnosticar, de fato, influências para o aproveitamento da mágica como uma ferramenta inovadora na terapia infantil.

Então, todos os aspectos tratados neste estudo, se refletem diretamente nas manifestações ligada à mágica como contribuição na vida de uma pessoa, em especial as crianças em terapia, sendo este a discussão central da pesquisa.

Partindo desse pressuposto, não se pretende afirmar que a mágica é a solução plena para superar as dificuldades na terapia, mas aparece como uma possibilidade e propósito de refletir sobre si mesmo, com um olhar voltado para a criança e esta, por sua vez, identificar no terapeuta um suporte para a construção da autonomia, com uma comunicação espontânea diante dos questionamentos e queixas apresentadas.

Pelas argumentações debatidas neste estudo, Pereira (2008) corrobora com a hipótese de que as transformações mais profundas requerem uma mudança de atitude e novas posturas de vida.

Portanto, é possível acreditar que através deste estudo sobre a experiência prática com o uso de mágica, abre-se um caminho dentro do cotidiano psicoterápico para a integração dos vários aspectos do ser humano, sejam eles: cognitivo, lúdico, emocional e outras habilidades proporcionadas pelo o uso da técnica, possibilita a cada individuo (paciente e terapeuta) se conhecer um pouco mais, se relacionar melhor, criar vínculo afetivo, o que implica lidar melhor com as dificuldades no processo de terapia, possibilitando uma expressividade mais espontânea e criativa.

Finalmente, espera-se que este tema gere inquietações para ampliar a discussão acerca do uso da mágica, não apenas como arte, mas como outras modalidades que sejam relevantes para o entendimento do processo terapêutico e, enfim, no contexto de comunicação em geral.

Recomenda-se, então, o uso da mágica como recurso alternativo na psicoterapia infantil, podendo ser estendida a outros públicos, haja vista que a mágica é uma técnica atrativa para qualquer faixa etária. 
Id on Line Revista Multidisciplinar e de Psicologia

Id on Line Multidisciplinary Journal and Psycology

\section{Referências}

ÁVILA, Guilherme. A arte mágica: a percepção em perspectiva. Brasília: Kiron, 2012. p. 216.

AXLINE, Virginia Mae. A dinâmica interior da infância. $2^{\mathrm{a}}$ ed. Belo Horizonte/MG.

INTERLIVROS, 1984.

BAUER, Martin W.; GASKELL, George (Ed.). Pesquisa qualitativa com texto, som e imagem: um manual prático. Tradução: Pedrinho A. Guareschi. Petrópolis: vozes, 2002. Tradução de: Qualitative Researching With Text, Image and Sound.

GATTI, Bernadete A. Estudos quantitativos em educação. Fundação Carlos Chagas. Educação e Pesquisa, São Paulo, v.30, n.1, p. 11-30, jan./abr. 2004.

GRAVENOR, Misha. Revista Scientific American Brasil. Mágicas e truques que iludem o cérebro. 2014. Disponível em: http://www2.uol.com.br/sciam/reportagens/magica_e_truques_que_iludem_o_cerebro.html. Acesso em 20 de outubro de 2015.

KARLING, Argemiro Aluísio. A didática necessária. São Paulo, Ibrasa, 199.

LUCKESI, Cipriano Carlos (org). Educação e Ludicidade. Salvador: UFBA, 1999.

LURIA, A. R. A construção da mente. Tradução Marcelo Brandão Cipolla. São Paulo, SP: Ícone, 1992.

MINAYO, M. C. S. et al. Pesquisa social: teoria, método e criatividade. Petrópolis: Vozes, 1994.

PEREIRA, Lucia Helena Pena. Bioexpressão: a caminho de uma educação lúdica para a formação de educadores, 2005, 388p. Tese (doutorado) - Programa de Pós-Graduação em Educação, Faculdade de Educação, Universidade Federal da Bahia, Salvador, 2005.

SOUZA, Rodrigo Dal Ben; et al. V Congresso de Psicologia UNIFIL: II Congresso Nacional de Psicologia. Londrina, PR, 2012. Disponível em:

http://www.unifil.br/portal/arquivos/publicacoes/paginas/2012/8/494_809_publipg.pdf. Acesso em: 15 de outubro de 2015.

VALLADARES, Ana Cláudia Afonso. A Arteterapia Humanizando os espaços de saúde. Ed. 1. São Paulo: caso do psicólogo, 2008.

VIGOTSKI, L. S. A construção do pensamento e da linguagem. São Paulo:Martins Fontes; 2001.

WINNICOTT, D. W. O brincar e a realidade. Rio de Janeiro. Imago Editora Ltda. 1995. 
Id on Line Revista Multidisciplinar e de Psicoloqia

Id on Line Multidisciplinary Journal and Psycology

\section{Como citar este artigo (Formato ABNT):}

GUEDES, J.D.; GONÇALVES, F.R.B. Magicoterapia: o uso de mágicas contextualizadas como instrumento para auxiliar na ludoterapia. Id on Line Revista Multidisciplinar e de Psicologia, Julho de 2016, vol.10, n.30, Supl. 3, p. 84-98. ISSN 1981-1179.

Recebido: 22/06/2016

Aceito: $13 / 07 / 2016$ 